\title{
Esclarecendo Dúvidas e Validando Certezas - Uma ferramenta de apoio à construção de conhecimento no contexto de Projetos de Aprendizagem
}

\author{
Luis Carlos Fonseca, Crediné Silva de Menezes, Rosa Maria Vicari, Lea da Cruz \\ Fagundes
}

Resumo: Uma das fontes para o desenvolvimento de P.A. são os documentos da WEB, entretanto crianças do ensino fundamental encontram enormes barreiras para as suas buscas devido a fatores tais como: a linguagem de expressão do que se deseja buscar, a orientação sintática, os erros de grafia, vocabulário, falta de organizadores dos resultados, etc. Neste artigo apresentamos uma proposta para ferramentas de apoio à construção de conhecimento no contexto de P.A., que tenha como um dos elementos um front-end para as máquinas de buscas disponiveis na Internet. Apresentamos ainda um protótipo desta ferramenta, construído para o projeto AMADIS, um software para apoiar a Projetos de Aprendizagem, financiado pelo edital de software livre da FINEP.

\section{Introdução}

As novas tecnologias da informação estão revolucionando as práticas pedagógicas, viabilizando a implantação de teorias pedagógicas conhecidas e contribuindo para o surgimento de novas. Alunos e professores dispõe hoje de novas possibilidades de exercitar os seus potenciais cognitivos, contribuindo assim para um melhor desenvolvimento de nossas habilidades intelectuais de nível superior (Fagundes, 1999).

As teorias pedagógicas tradicionais são baseadas principalmente na informação e na memorização. Estudos recentes mostram que a aprendizagem propiciada pela aplicação dessas teorias não desenvolve no aluno habilidades cognitivas e criativas, para que seja capaz de analisar e discutir pontos de vista e solucionar problemas, sendo, portanto, ineficiente para atender às necessidades da sociedade moderna.

Esses estudos motivaram o surgimento de modelos de educação alternativos, não presenciais e abertos, baseados no uso do computador e da tecnologia da informação. Um dos modelos mais conhecidos é a educação à distância (EAD), mas também nos cursos presenciais pode-se aproveitar o potencial da telemática para enriquecer o conteúdo das disciplinas curriculares e propiciar a interação dos alunos com pessoas de outras comunidades, trazendo especialistas de todas as áreas para o ambiente escolar (Lucena, 1997).

Uma pesquisa realizada com 51 escolas brasileiras de $1^{\circ}$ e $2^{\circ}$ graus (Campos et al., 1999) mostrou que o total de escolas que adotaram o computador na prática educacional e o número de equipamentos adquiridos aumentou significativamente nos últimos anos As práticas adotadas todavia, têm, predominantemente, caráter conservador, reforçando o modelo behaviorista de aprendizagem em detrimento das teorias construtivistas, as quais vêm sendo preferidas pela pesquisa acadêmica e pelas diretrizes governamentais, no uso da informática na educação, por possibilitarem a reorganização da atual estrutura do processo de escolarização.

Em nossas pesquisas de inserção da informática nas práticas pedagógicas temos experimentado, com relativo sucesso, uma nova abordagem denominada Projetos de 
Aprendizagem (FAGUNDES, 1999; BASSO, 2005). Em termos de metodologia, o primeiro passo é identificar um questionamento do estudante sobre um determinado aspecto de seu universo, que para fins didáticos, denominamos de "Questão de Investigação". A seguir é feito um inventário dos conhecimentos (sistemas nocionais, ou conceituais dos aprendizes) sobre a questão. Esse conhecimento pode ser classificado em dúvidas e certezas. As certezas para as quais não se conheça os fundamentos que a sustentem são denominadas de provisórias. As dúvidas são sempre temporárias. $\mathrm{O}$ processo de investigação consiste no esclarecimento das dúvidas e na validação das certezas.

Para dar suporte a esta pedagogia estamos desenvolvendo o Projeto AMADIS, um software livre, financiado pela FINEP, para realização de atividades educacionais cooperativas, através da Internet. Neste artigo apresentamos uma das ferramentas consideradas no projeto, uma interface para facilitar a recuperação de documentos na web. A ferramenta buscará a inserção de facilidades inteligentes que auxiliem na descrição de consultas para recuperar informação e deverá ser adequada ao uso por crianças do ensino fundamental.

Na seção 2 fazemos uma discussão sobre projetos de aprendizagem, a seção 3 apresenta os requisitos de uma ferramenta baseada na web para apoiar a pedagogia de projetos, na seção 4 apresentamos uma proposta para a ferramenta. A seção 5 descreve uma versão corrente para a ferramenta proposta. Finalmente fazemos as considerações finais.

\section{Projetos de Aprendizagem}

Uma diferença marcante entre projeto de ensino e projeto de aprendizagem é a possibilidade do aprendiz se envolver desde o princípio com os rumos de sua aprendizagem. Entendemos que a aprendizagem ocorre quando o sujeito se envolve com a resolução de problemas que lhe dizem respeito, quando busca entendimento das coisas que lhe importa, que povoam seu universo. O que mais importa na formação de um sujeito é prepara-lo para uma leitura do mundo que lhe permita identificar problemas e instrumenta-lo para buscar solução para estes problemas.

É com este propósito que um projeto de aprendizagem parte do sujeito, de suas interações com o mundo, da falta de explicação para os fenômenos físicos, sociais e culturais de seu mundo, uma "questão de investigação". É por uma questão, portanto que tudo começa, é um incentivo ao aguçamento das curiosidades, é um ponto de partida para a formação de indivíduos autônomos.

Em um momento seguinte, o aprendiz se dedica a fazer um inventário das idéias que ele associa com sua questão. Podemos agrupar essas idéias em dois blocos, certezas e dúvidas. Elas farão parte do suporte metodológico para a viagem que será feita. As dúvidas são temporárias e na viagem iremos buscar elementos para esclarece-las. As certezas são provisórias, dado que em nossa viagem devemos valida-las e, eventualmente, até refuta-las.

Para fazer esta viagem os aprendizes fazem planos, organizam as certezas e dúvidas de uma forma lógica, escolhem uma ordem para a investigação. A cada etapa da viagem, colhem dados, analisam, fazem conexões, sintetizam, afloram novas dúvidas e certezas.

A coleta de dados, o ponto de partida para a validação das certezas e para o esclarecimento das dúvidas, ocorre de várias maneiras, usando diversas fontes, sendo 
que as mais comuns são: observação, entrevistas, enquetes, leituras e simulações. Neste artigo focamos nossa atenção na busca por material de leitura na Internet.

\section{Busca na Internet e Projetos de Aprendizagem}

A internet abriga hoje bilhões de documentos, hospedados em sites distribuídos em um grande número de países. Não se sabe exatamente qual a quantidade de documentos disponíveis, mas temos certeza que este número é bastante grande e que cresce rapidamente. Existem documentos na internet tratando, em diferentes níveis de abstração e detalhes, de um número bem vasto de temas. Nunca se teve acesso a um número tão vasto de documentos tratando de um número tão diversificado de assuntos. $\mathrm{O}$ advento da internet é um divisor de águas no acesso à informação.

A internet, mais precisamente a WEB, se constitui hoje em uma valiosa fonte de informação. Nela podemos encontrar textos de mais diferentes natureza e fontes. Podemos encontrar na WEB artigos científicos, noticias de jornal, leis, documentos históricos, entrevistas, livros, entre outros. Estas informações estão distribuídas em sites localizados nas mais diversas partes do planeta, tornando-se praticamente impossível conhecer o que existe e localizar uma informação de interesse sem um auxílio de um mecanismo computacional.

A recuperação destes textos se tornou possível a partir da criação dos mecanismos de buscas e sites com informações indexadas dentro de uma certa organização. Os primeiros, também chamados de diretórios, oferecem uma árvore de indexação na qual podemos navegar em busca de documentos específicos. Os sites para recuperação, também chamados de sites de busca, oferecem uma linguagem para o usuário descrever o que pretende recuperar (termos de busca).

Os sites de busca realizam de fato um trabalho fantástico, colocam em nossas mãos milhares de textos, com um simples clicar em um botão. Mas o que fazer com esses textos todos? Será que todos eles servem? Os sites de busca possuem um critério de relevância que lhes permite apresentar os textos em uma dada ordem, do mais relevante para o menos relevante. Qual a relação entre os critérios de relevância dos sites e o que de fato é relevante no contexto da construção de conhecimento a partir do desenvolvimento de Projetos de Aprendizagem?

Antes de clicarmos para acionar a busca, precisamos informar palavras relevantes para orientar a seleção de texto. Que palavras escolher? Quantas palavras é preciso informar? E se eu desconhecer a grafia correta da palavra, como fazer? Os sites de busca tratam de sinônimos?

A título de ilustração, vamos considerar que em um determinado projeto de aprendizagem queiramos elucidar a dúvida: "Como surgiu a música?". Usando o "Google", um dos sites de busca mais utilizados, teremos o resultado apresentado na figura 3.1 . 


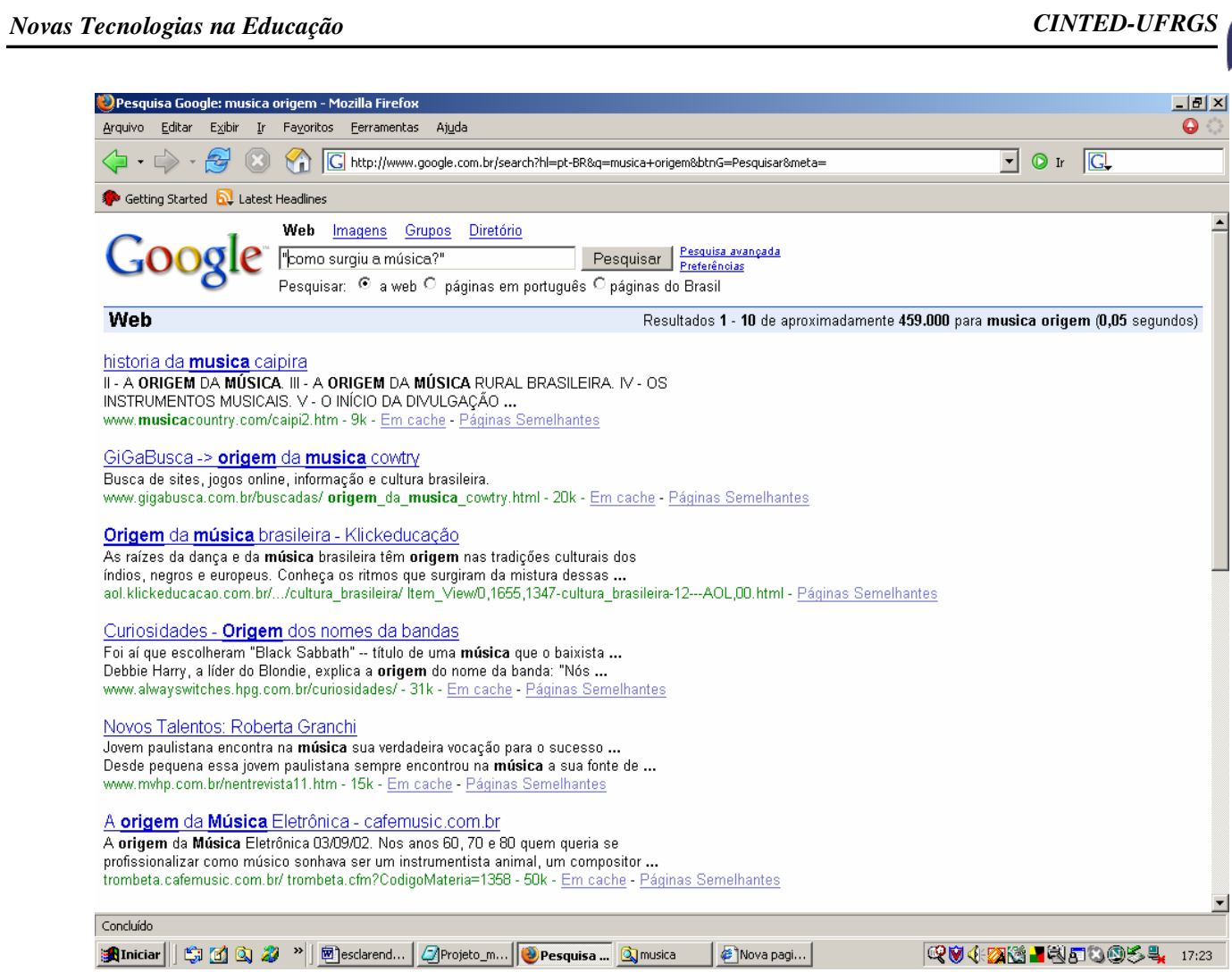

Figura 1: Resultado de uma consulta ao Google para a frase "Como surgiu a música?"

Olhando a listagem apresentada é razoável perguntar:

- Será que nesta lista de textos estão inclusos os textos que seriam selecionados com a frase "Qual a origem da música?".

- Os textos selecionados possuem uma fonte confiável? Como saber se um determinado texto é de fato útil ou é apenas um lixo internáutico?

- Tudo que existe na Internet pode ser recuperado por meu site de busca preferido?

Esses são alguns dos questionamentos que surgem quanto resolvemos usar a Internet como fornecedor de documentos para as leituras dos alunos durante o desenvolvimento de um projeto de aprendizagem.

\section{As máquinas de busca são "orientadas a palavras"}

Os mecanismos de buscas disponíveis, ou os mais utilizados disparam recuperação da informação através de termos ou parâmetros de buscas baseados em palavras, como exemplos podemos citar, o google, Altavista, Yahoo, NetSearch e vários outros. O que acontece normalmente é que os resultados de uma consulta apontam em várias direções com montantes de links na casa dos milhares, tornando uma tarefa bastante difícil para o usuário pinçar uma ou duas informações que lhes interessam, muitas das vezes até não encontram o que estão procurando. A busca orientada por palavras, corre um risco muito grande de palavras dicotômicas, pois estamos procurando por "apple" computadores e retornar "apple" frutas e assim por diante.

Pode-se dizer que os métodos convencionais de busca por documentos baseados em palavras se assentam na hipótese de que um documento ou contém uma palavra ou não 
a contém, não há meio termo. Ao contrário, leitores, procuram documentos onde o assunto subjacente a uma palavra está presente. Em outras palavras, olhamos para um documento como um todo e não como uma sequiência de palavras.

O desenvolvimento de técnicas para recuperação de informação antecede o surgimento da web (Salton, 1983), mas só foi o advento desta que, por seu alto grau de capilaridade, motivou a pesquisa por técnicas sofisticadas de busca em coleções de documentos de grande porte (Baeza-Yates, 1999). Não se trata agora de recuperar documentos em coleções temáticas. As páginas da internet tratam de qualquer coisa, sem catalogação especializada. O grande desafio é encontrar documentos relevantes para uma dada necessidade dos usuários. Por causa do grande volume de documentos, sabemos que existem respostas possiveis para quase qualquer consulta formulada. Entretanto, o tipo de modelo de recuperação utilizado pode esconder uma grande quantidade dos documentos que serviriam de resposta a uma dada consulta. Além disso, nem tudo que está na internet vale a pena ser lido.

\section{Uma proposta para o Sistema e Apoio a Recuperação de Documentos}

No intuito de suportar o serviço de auxilio ao desenvolvimento de Projetos de Aprendizagem está em desenvolvimento um ambiente que servirá de front-end para busca de documentos na Internet. A seguir são definidas algumas das funcionalidades básicas que a ferramenta deverá implementar.

Conforme a Figura 2, estão descritos a seguir alguns casos de uso relevantes à proposta da ferramenta, agrupadas pelos os atores do sistema:

- Para o ator Aluno:

- Buscar textos relevantes: Acredita-se que os processos de aquisição de documentos pode se dar pela iniciativa do aprendiz, entretanto, as definições de quais eventos iniciarão essa atividade ainda estão em estudos. Os documentos obtidos como resultado dessas consultas serão armazenados em uma base de dados de textos relevantes;

- Construir vocabulário: É onde o aprendiz poderá manipular os termos utilizados nas consultas feitas à internet tais como os termos próprios do vocabulário do P.A., sinônimos desses termos e palavras com grafia errada;

- Navegar nos documentos: Interface de navegação (Browsing) nos documentos relevantes recuperados pela ferramenta de R.I. do sistema. Há também uma ferramenta de indexação automática dos documentos para facilitar essa navegação;

- Descrever P.A.: Meio pelo qual o aluno poderá criar e modificar os P.A.'s definindo assim os dados a eles relacionados tais como: a Questão de Investigação e os Itens de Conhecimento (Certezas e Dúvidas);

- Avaliação de documentos: os alunos, após analisarem um documento recuperado pelo sistema, poderão emitir um laudo sobre a qualidade dos documentos, com respeito ao conteúdo, à adequação da linguagem, à veracidade etc, informações que ajudam na aprendizagem do grupo sobre o uso de documentos, mas que também podem auxiliar o sistema na seleção de páginas da internet em sua próximas buscas;

- Para o ator Professor:

- Recomendação de Textos: O professor no ambiente poderá dentre outras coisas recomendar textos relevantes para um determinado PA. Tendo assim 
um papel de orientador/facilitador do processo de aprendizagem.

- Construir vocabulário - o professor poderá, assim como os alunos, associar palavras, por diferentes graus de relação, tais como sinônimos e variações ortográficas.

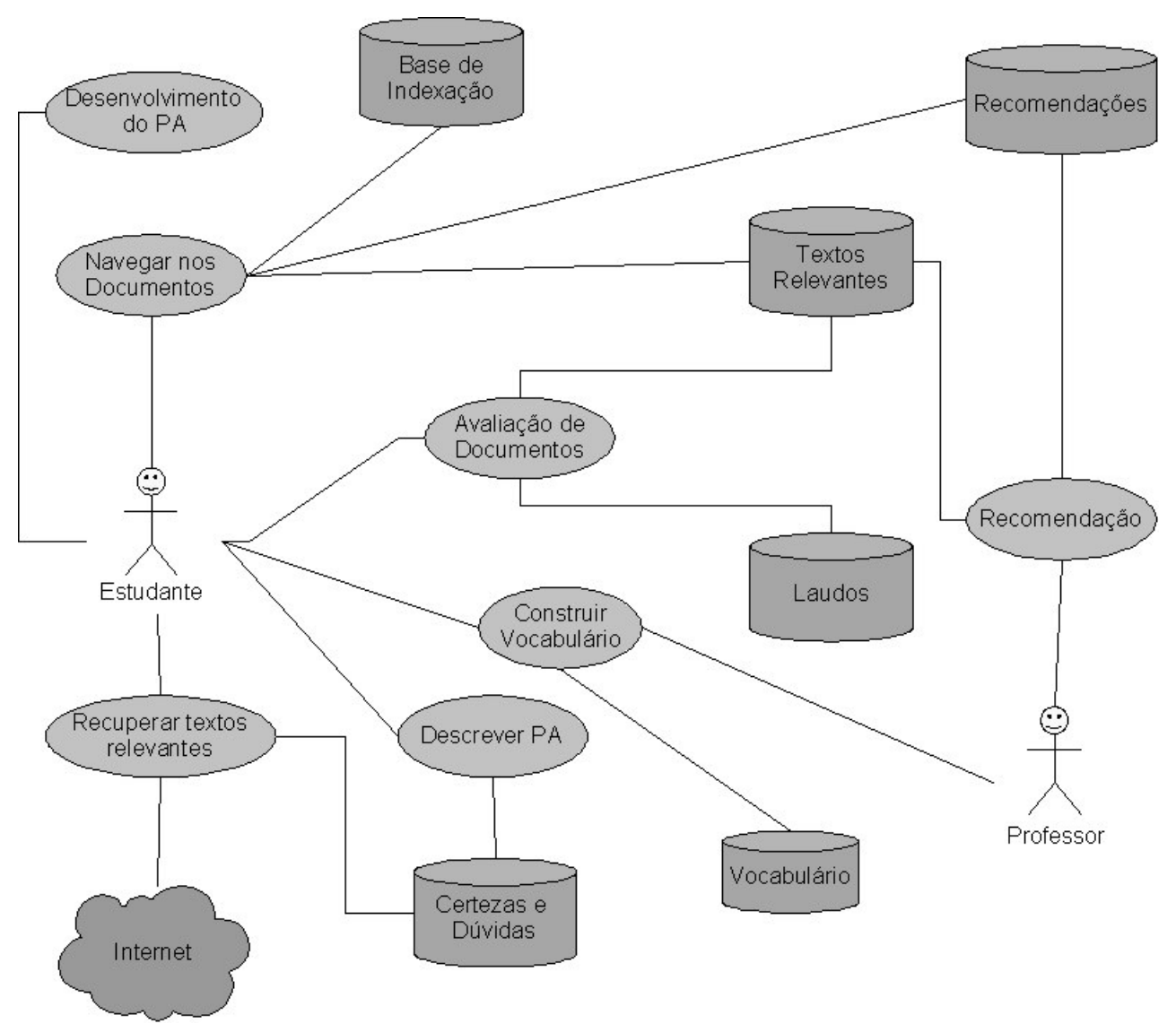

Figura 2: Casos de Uso para a interface de RI para apoio a Projetos de Aprendizagem

\section{A primeira versão do Sistema}

Em uma primeira versão do que pretende-se implementar para o ambiente proposto, foi desenvolvida uma ferramenta de catalogação do que chamamos de Itens de Conhecimento (IC) (Certezas e Dúvidas), onde cada um desses poderá ser cadastrado no sistema para posteriormente ser analisado (validado ou refutado). A unidade central da busca de textos é um Projeto de Aprendizagem, individual ou coletivo. Para cada projeto cadastramos "itens de conhecimento" que darão contexto ao processo de busca. Na Figura 3 é apresentada a interface principal do sistema. 


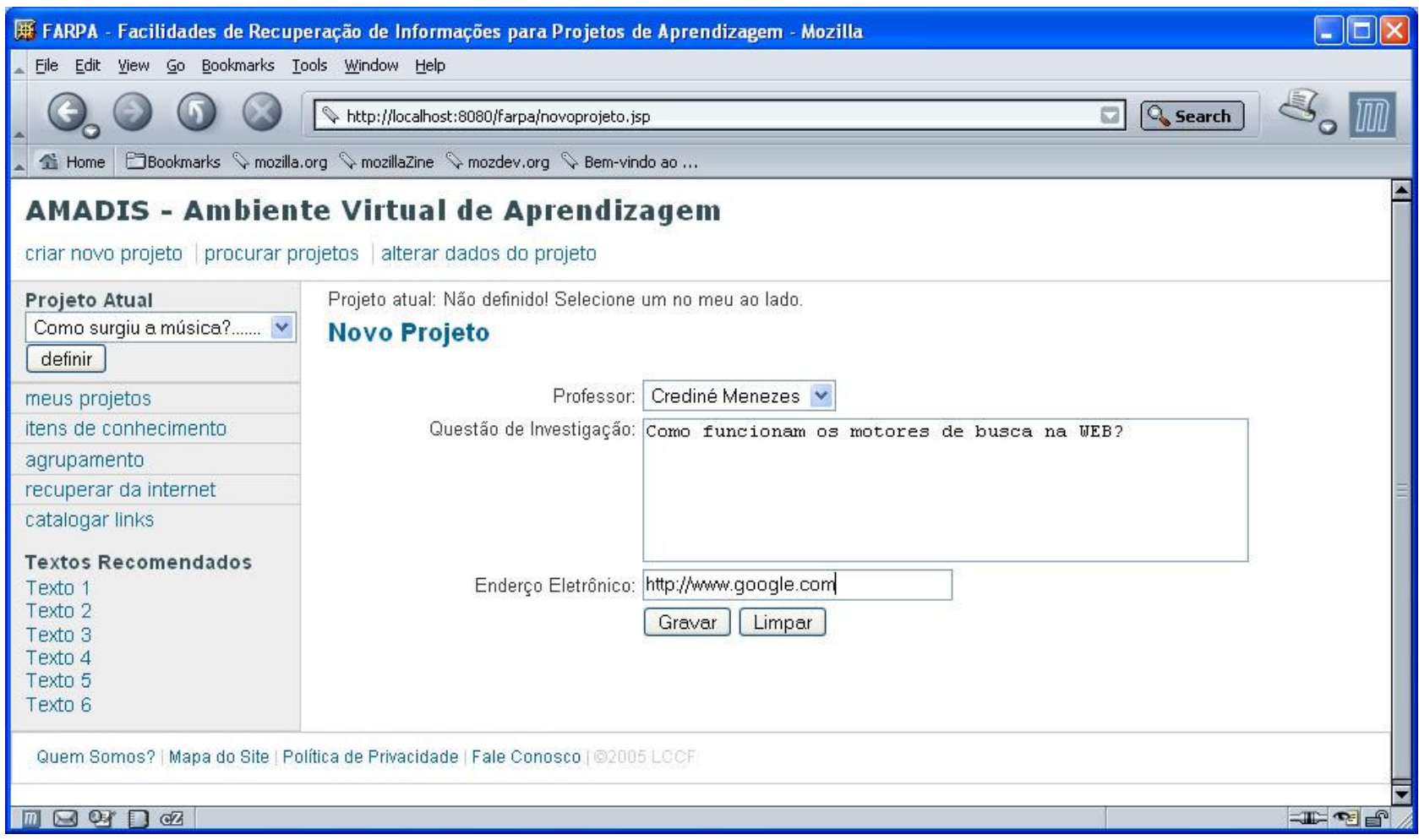

Figura 3: Tela principal do ambiente proposto para apoio à Recuperação de Informação do AMADIS

A importância do trabalho de catalogação de IC's foi melhor entendida quando começou-se a pensar em criar facilidades de busca (Recuperação de Informações) a partir dos motores de busca, pois sabe-se que o mau uso dessas ferramentas pode diminuir a qualidade das informações devolvidas. Essas facilidades estariam encapsuladas em um Front-End do sistema proposto e serviriam para evitar (ou deixar transparente ao usuário) o trabalho de codificação nos motores de busca. A Figura 4 apresenta a interface do sistema para apresentação do resultado da consulta realizada sobre um determinado item de conhecimento.

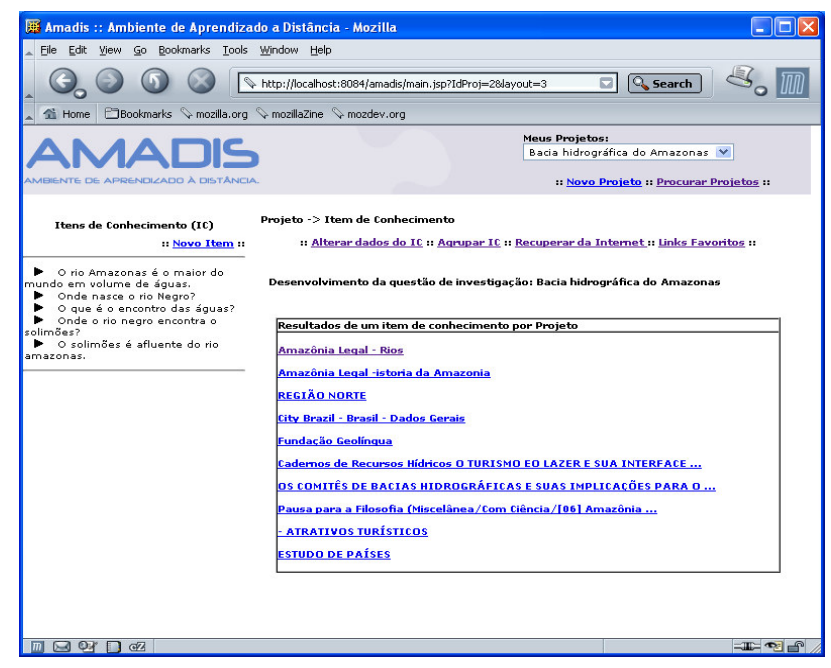

Figura 4: Tela do protótipo que mostra a Recuperação de Informações de um projeto

A partir dessa análise foi considerada a possibilidade de descobrir as "Expressões de Busca" que consistem em subdivisões dos conceitos extraídos dos Itens 
de Conhecimento, e que definem uma consulta com resultados potencialmente mais próximos do contexto que se quer recuperar. Essas expressões podem servir para indexação dos resultados obtidos na consulta ou como palavras-chaves nas consultas submetidas.

Agora, com os documentos recuperados, trataremos esses resultados de forma a eliminar páginas irrelevantes ao contexto de estudo. Para tanto se encontra em estudos o uso de Latentic Semantic Indexing - LSI que consiste no uso de índices conceituais derivados de dados estatísticos ao invés de palavras individuais para a recuperação. $\mathrm{O}$ LSI supõe que há alguma estrutura subjacente ou latente no uso das palavras que é obscurecido parcialmente pelas flexões gramaticais utilizadas. A idéia é projetar consultas e documentos em um espaço com dimensões semânticas "latentes". No espaço semântico latente, uma consulta e um documento podem ter a similaridade elevada mesmo se não compartilham de nenhum termo.

Com essa métrica pode-se definir os documentos mais relevantes e apresentá-los aos aprendizes de forma a contribuir na validação dos Itens de Conhecimento dos projetos de aprendizagem.

\section{Considerações Finais}

Apresentamos neste artigo a proposta de um ambiente para facilitar o trabalho de crianças do ensino fundamental na busca por documentos na Internet. Os aspectos principais considerados na ferramenta são as dificuldades encontradas pelas crianças quando usam os sites de busca convencionais.

A ferramenta atualmente em fase de testes preliminares será, posteriormente, testada com professores e alunos de escola pública, visando identificar inadequações e novas necessidades.

De forma paralela, o trabalho prossegue com a implementação de novas facilidades que melhorem a interface para as crianças de forma a tornar o sistema mais amigável.

A versão corrente considera como termos apenas palavras isoladas, em novas versões implementaremos o reconhecimento de "Expressões de Busca" a partir dos Itens de Conhecimento catalogados. O repositório de conteúdos utilizado pelo ambiente inicialmente é a WEB, pretendemos realizar uma extensão do módulo de RI para suportar a recuperação de objetos de aprendizagem.

\section{Referências Bibliográficas}

FAGUNDES, L., Maçada, D., Sato, L. Aprendizes do Futuro, as Inovações Começaram, MEC, 1999.

JAQUES, Patrícia A. Using an Animated Pedagogical Agent to Interact Affectively with the Student. 2004. Tese (Doutorado em Ciências da Computação) Instituto de Informática, UFRGS, Porto Alegre.

MAgdalenA, B., Pernigotti, J., Dutra, I. Camargo, F., Valentini, N., Lacerda, R. Gonzalez, Yara. Projeto Amora 2000, 1999. Acesso via web em julho de 2004: http://amora.cap.ufrgs.br/2000/documentos/ProjetoAmora2000.doc 
FONSECA, Luís Carlos; MACHADO, Nadie; KAMPFF, Adriana; GOMES, Fábio; LIRA, Antonio; BERCHT, Magda; REITZ, Dóris. Relação entre o Perfil do Usuário e a Escolha do Perfil do Tutor. Revista de Novas Tecnologias na Educação, volume 3, número 1, CINTED-UFRGS, 2004

NEVADO, R.A., Basso, M. V. A , Bittencourt, J. V. AMADIS: Ambiente de Aprendizagem a Distância para Formação Continuada de Professores. Revista Informática na Educação - Teoria e Prática, volume 4, número 2, PGIEUFRGS, 2001.

ROSÁRIO, Bárbara. Latent Semantic Indexing: An overview. Infosys 240, Final Paper. 2000

BASSO, M.V.A; Nevado, R.A.; Fagundes, L.C; Bittencourt, J.; Menezes, C.S.; Projetos de Aprendizagem - Uma experiência mediada por ambientes telemáticos; XII Workshop de Informática na Escola, CSBC, São Leopoldo-RS, julho/2005.

SALTON, G., \& McGill, MJ (1983). Introduction to modern information retrieval. NY: McGraw-Hill.

BAEZA-YATES, R., Ribeiro-Neto, B.; Modern Information Retrieval, Addison Wesley Longman, 1999. 